\title{
Universal Access to Essential Medicines: An Evaluation of Nepal's Free Health Care Scheme
}

\author{
Shiva Raj Adhikari, ${ }^{1}$ Achyut Raj Pandey, ${ }^{2}$ Mamata Ghimire, ${ }^{3}$ Arjun Kumar Thapa, ${ }^{4}$ Dinesh Kumar Lamsal ${ }^{5}$ \\ ${ }^{1}$ Patan Multiple Campus, Tribhuvan University, Lalitpur, ${ }^{2}$ Nepal Health Research Council, Ramshah Path, \\ Kathmandu, ${ }^{3}$ Institute for Nepal Environment and Health System Development, Kathmandu, ${ }^{4}$ Faculty of \\ Humanities and Social Sciences, Pokhara University, Dhungepatan, Kaski, ${ }^{5}$ Civil Service Hospital, Minbhawan, \\ Kathmandu, Nepal.
}

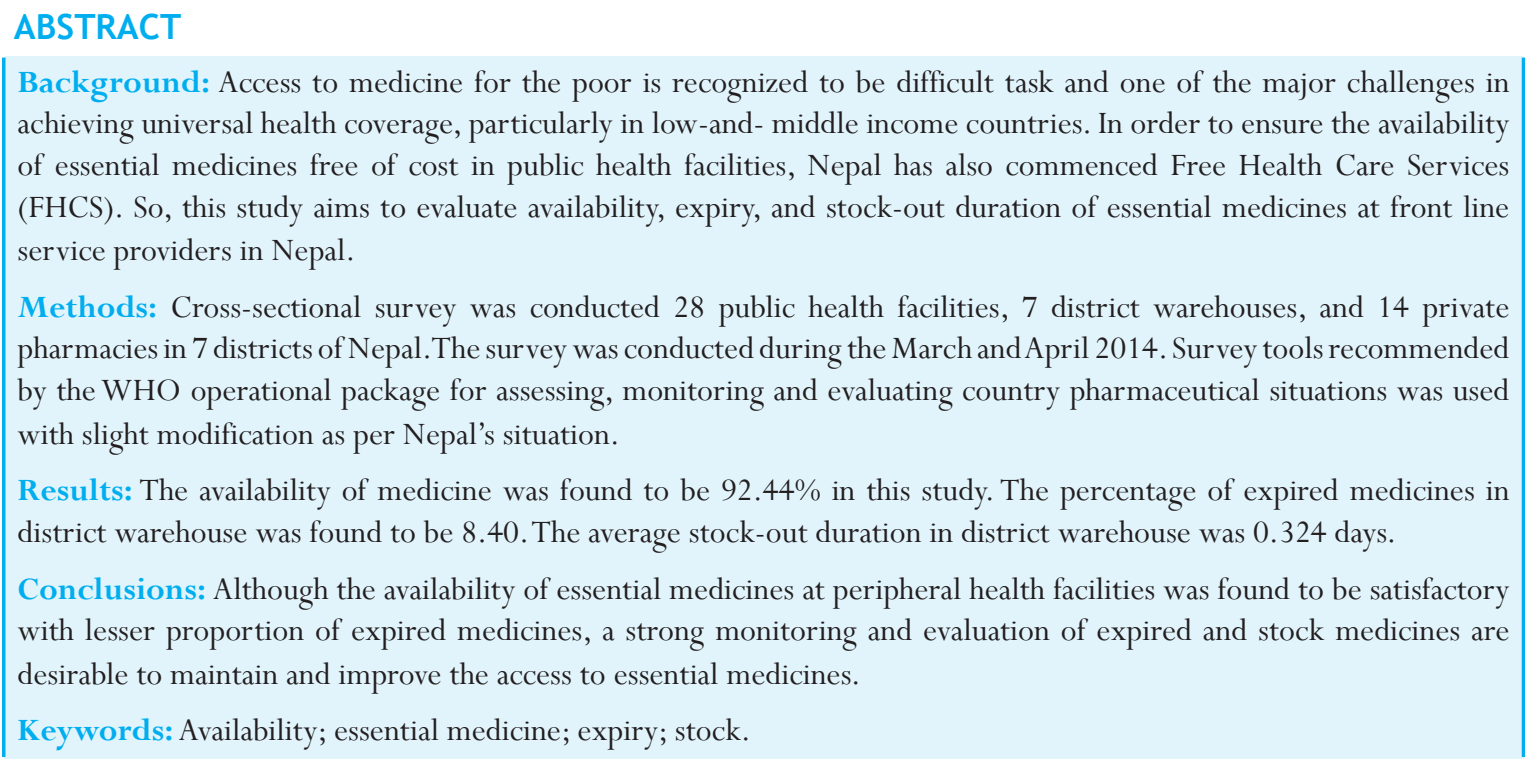

INTRODUCTION

In the context of functioning health systems, essential medicines are intended to be available all the times in adequate amounts, in the appropriate dosage forms, with assured quality, and at a price the individual and the community can afford. ${ }^{1-3}$ The universal health coverage (UHC)is central to the Sustainable Development Goals (SDGs) put forward by the United Nations (UN). ${ }^{4}$ Furthermore, universal access to essential medicine is fundamental to the attainment of the UHC.Although the need to improve the availability of affordable medicines for the world's poor has been acknowledged by the MDGs and SDGs,more than half of those poor have no regular access to essential medicines. ${ }^{4-7}$ The Government of Nepal (GoN) commenced the Free Health Care Services (FHCS) in 2008 hoping to improve the access of essential medicines at public health facilities. ${ }^{8}$ Despite this significant policy transition, shortage of medicine is said to have undermined the health system performance in Nepal.

This study aimed to assess the current situation in the availability of essential medicines in Nepal following the guidance laid out by the WHO to evaluate access to essential medicine. ${ }^{9}$

\section{METHODS}

For the primary data collection, the public health facility survey tools recommended by the WHO Operational package for assessing, monitoring and evaluating country pharmaceutical situations was used with slight modificationas per Nepal's situation and focused on acquiring the information on availability and quality of medicine. ${ }^{9} \mathrm{~A}$ total of 15 essential medicine from list of survey instrument recommended by WHO that are basic requirements at all levels of health care and two additional medicines widely used in Nepal considering prevailing disease pattern as suggested by the experts were assessed. The list of essential medicine assessed in this study was- Paracetamol (Tab, sus), Albendazole (Tab), Metronidazole (Tab, sus), Amoxicillin (Tab, cap), Sulfamethoxazole +Trimethoprim (Tab, Sus), Ferrous Salt +Folic Acid (Tab), Povidonelodine Solution, Aluminium hydroxide + Magnesium hydroxide (Tab), Oral Rehydration solution (ORS) powder, Compound solution of Sodium lactate (Ringers' Lactate) inj, Sodium Chloride inj, Ciprofloxacin Tab, Salbutamol Tab., Gentamycin inj, Dextrose Solution inj, Oxytocin, Magnesium Sulphate.

This study was carried in 7 districts out of 75 districts Kathmandu, Nepal. Email: achyutrajpandey2014@gmail.com, Phone: +9779849215398. 
in Nepal. Those randomly selected districts well represented the heterogeneity of the country in terms of ecological and administrative variations. Total of 28 public peripheral health facilities (health facilities below the district level) - 7 Primary Health Care Centres (PHCCs), 7 Health Posts (HPs), and 14 Sub Health Posts (SHPs) and 14 private pharmacy nearby public facilities in 7 districts were surveyed. Additionally, 7 district warehouses were also surveyed.

The survey was conducted during the March and April 2014. Availability of medicine at the time of visit was based on direct observation of the specified medicine in the dispensary and selves of the public as well private health facilities. Presence of expired medicines in health facilities was assessed by randomly checking expiry date of each of seventeen different medicines considered in this study. To calculate the stock-out duration for a complete year, stock registers were reviewed dated September 2012 to August 2013.

During the survey, data and information collected were checked for completeness. Missing data were immediately completed through re-visits to health facilities whenever needed. Regulatory compliance of the drug was assessed by direct observation of drug storage room and dispensary. Following of First Expiry First Out (FEFO)was considered acceptable if the medicines are stored according to drug expiry date with drug having short expiry duration on the outer part and drug having long expiry data in the inner part of cabinet.

Data entry and analysis was done in Microsoft excel. Percentage of health facilities with adequate record keeping, percentage of essential medicines available in health facilities, percentage of expired essential medicines in health facility and average stock-out duration in days were key indicators used in this study to assess the access of essential medicine in Nepal.

Key indicators were calculated using formula as suggested in the WHO manual and presented descriptively. ${ }^{9}$ Percentage adequate stock records or adequacy of record keeping was computed as number of incidences where there are adequate records for at least 6 months divided by number of key medicines reviewed and multiplied by 100. To calculate the percentage of medicines available, the number of medicines available in the facility was divided by the number of medicines under study and then multiplied by 100 . The similar rule of calculation was applied for expired medicines district warehouse, peripheral health facilities and private health facilities. Stock-out duration was calculated based on the store register that indicated which medicines have records covering at least 6 months within the previous 12 months. A medicine was considered in stock if it was available in generic or branded form. The number of days out of stock of particular medicines was based on the sum of number of days the medicine was out of stock in store register.

\section{RESULTS}

The availability of medicine was found to be $92.44 \%$ in this study. The percentage of expired medicines in district warehouse was found to be 8.40. The average stock-out duration in district warehouse was 0.324 days (not presented in table).

More than $90 \%$ of medicines were available in stock in all three levels of health facilities namely PHCCs, HPs and SHPs. On an average, 3 percentage of essential medicines were found to have been expired in both HPs and SHPs while only around 1 percentage of medicines were found to have expired in PHCCs (Table 1). Table 1. Key indicators to access of essential medicine in Nepal.

Peripheral Health Facilities

\begin{tabular}{lrrr}
\hline Indicators & PHCC & HP & SHP \\
\hline Stock of Medicine (\%) & 91.59 & 96.42 & 98.2 \\
\hline Expired Medicine (\%) & 0.89 & 3.04 & 2.55 \\
\hline Stock out duration of & 5.36 & 2.31 & 4.77 \\
Medicine (no. of days) & & & \\
\hline
\end{tabular}

Availability of selected essential medicine at district warehouse, public and private health facilities.

As shown in figure 1 , the average availability of medicine at district warehouse of mountain and hill was 94\%; while, $82 \%$ of medicine were found in stock at the time of visit in tarai. Only one district warehouse of fivedevelopment regions- Far-western development region (FWDR) offered $100 \%$ of key essential medicines. Other regions had availability below $95 \%$.

PHCC in mountain region had all essential medicine in stock while around $98 \%$ and $88 \%$ of essential medicines were available in PHCCs in tarai and mountain region. Also, stock of essential medicine was $100 \%$ in HPs in both tarai and mountain region of the country while it $6 \%$ points lower in hilly region. SHPs in all three ecological belts had medicine stock above 95\% (Table 2). Similarly, PHCCs in Mid-western Development Region (MWDR) had all essential medicines in stock while PHCCs in Eastern Development Region (EDR) and PHCCs in Central Development Region (CDR) had around 98\% of essential medicines in stock. Western Development Region (WDR) had only around $79 \%$ of essential medicines in stock. HPs in all development regions except WDR (87.5\%) was found to have all essential medicines in stock. Availability of essential medicines at the private outlets nearby the public health facilities was $81 \%$ in terai region and around $76 \%$ in mountain and hill region. The private outlets in EDR had highest (91\%) of essential medicine in stock. 
Table 2. Stock of essential medicines at public and private health facilities in Nepal.

\begin{tabular}{lrrrr} 
& \multicolumn{2}{c}{ Public (\%) } & \multicolumn{2}{l}{$\begin{array}{l}\text { Private } \\
\text { (\%) }\end{array}$} \\
& PHCC & HP & SHP & \\
\hline Ecological belt & & & & \\
Mountain & 100 & 100 & 96.15 & 76.47 \\
\hline Hill & 88.21 & 93.75 & 97.80 & 75.99 \\
\hline Tarai & 97.78 & 100 & 97.43 & 80.89 \\
\hline Development Regions & & & & \\
Eastern & 98.24 & 100 & 96.15 & 91.18 \\
\hline Central & 98.04 & 100 & 100 & 75.75 \\
Western & 76.36 & 87.5 & 100 & 76.47 \\
\hline Mid-western & 100 & 100 & 96.43 & 76.47 \\
\hline Far-western & 94.12 & 100 & 91.2 & 72.94 \\
\hline
\end{tabular}

District warehouse in tarai belt were found to have more expired medicines (11.76\%) in store (Fig 2) than warehouse of mountain and hill. Region wise, EDR had highest percentage $(11.76 \%)$ of expired medicines in store while no expired medicines were found in district warehouse of FWDR.

On an average, $3 \%$ of essential medicines were found to have been expired in both SHPs while in HPs only around $1 \%$ of medicines were found to have expired. SHPs in tarai region has the highest percentage $(12 \%)$ of expired medicine among the essential medicine list whereas PHCCs and HPs in the same belt apparently had no expired medicines in the store. SHPs in the hilly region has around $8 \%$ of expired medicine in store. (Table 3 )

Around $3 \%$ of essential medicines were found in expired state in private health facilities in mountain region whereas percentage of expired essential medicines was less than $1 \%$ in hilly region and nil in tarai region of Nepal.

The longest average duration of stock-out of medicine was found in SHPs of MWDR (20.86 days) of Nepal followed by WDR with only 2 days shorter stock out duration. All three levels of peripheral health facilities had shortest stock-out duration in EDR of Nepal (Table 4).
Table 3. Expired medicines at public and private health facilities in Nepal.

\begin{tabular}{lrrrr} 
& \multicolumn{2}{c}{ Public (\%) } & \multicolumn{2}{c}{ Private } \\
& PHCC & HP & SHP & $(\%)$ \\
\hline Ecological belt & & & & \\
Mountain & 1.47 & 6.25 & 0 & 2.94 \\
Hill & 3.75 & 3.75 & 8.09 & 0.49 \\
Tarai & 0 & 0 & 12.09 & 0 \\
Development Regions & & & & \\
Eastern & 0 & 0 & 3.85 & 0 \\
Central & 0 & 0 & 11.91 & 0 \\
Western & 0 & 7.45 & 0 & 0 \\
Mid-western & 6.25 & 6.25 & 0 & 2.94 \\
Far-western & 5.88 & 0 & 0 & 0.94 \\
\hline
\end{tabular}

Table 4. Stock-out duration (in days) of essential medicines at public health facilities in Nepal.

Public

\begin{tabular}{lrrr} 
& PHCC & HP & SHP \\
\hline Ecological belt & & & \\
Mountain & 6.56 & 19.01 & 34.04 \\
\hline Hill & 9.01 & 14.43 & 12.57 \\
\hline Tarai & 0 & 8.26 & 0.36 \\
Development Regions & & & \\
Eastern & 0 & 0.29 & 0.54 \\
\hline Central & 3.58 & 13.81 & 1.89 \\
Western & 7.85 & 6.66 & 18.54 \\
Mid-western & 6.56 & 19.1 & 20.86 \\
\hline Far-western & 9.57 & 0 & 10.50
\end{tabular}

Differences exist in the average stock out duration in HPs. In case of HPs, stock out duration in mountain region in more than double than that of tarai region. In all three levels of health facilities, tarai has the shortest stock out duration for essential medicines. Table 5 gives the summary of availability, expired, and out-of-stock essential medicines in the selected health facilities in Nepal.

Table 5. Availability, expiry, and stock-out duration of selected individual essential medicine in Nepal.
Private Health

Facilities

\begin{tabular}{|c|c|c|c|c|c|c|c|c|c|c|c|c|c|c|c|}
\hline & \multicolumn{3}{|c|}{ DPHO } & \multicolumn{3}{|c|}{ PHCC } & \multicolumn{3}{|c|}{ HP } & \multicolumn{3}{|c|}{ SHP } & \multirow[b]{2}{*}{$A$} & \multirow[b]{2}{*}{$E$} & \multirow[b]{2}{*}{$\mathrm{S}$} \\
\hline & A & $E$ & $\mathrm{~S}$ & A & $E$ & $S$ & A & $E$ & $S$ & $A$ & $E$ & $S$ & & & \\
\hline Paracetamol & 7 & 0 & 0 & 7 & 0 & 1.15 & 7 & 0 & 1.64 & 14 & 0 & 0.20 & 19 & 0 & - \\
\hline Albendazole & 7 & 0 & 0 & 6 & 1 & 0 & 7 & 0 & 0 & 14 & 0 & 0 & 19 & 0 & - \\
\hline Metronidazole & 7 & 0 & 0 & 7 & 0 & 0 & 7 & 0 & 0 & 14 & 0 & 2.32 & 20 & 0 & - \\
\hline Amoxicillin & 7 & 0 & 0 & 7 & 0 & 1.06 & 7 & 0 & 0 & 14 & 0 & 11.65 & 18 & 1 & - \\
\hline Cotrim & 7 & 1 & 0 & 7 & 0 & 1.27 & 7 & 1 & 0 & 14 & 1 & 6.52 & 13 & 0 & - \\
\hline
\end{tabular}




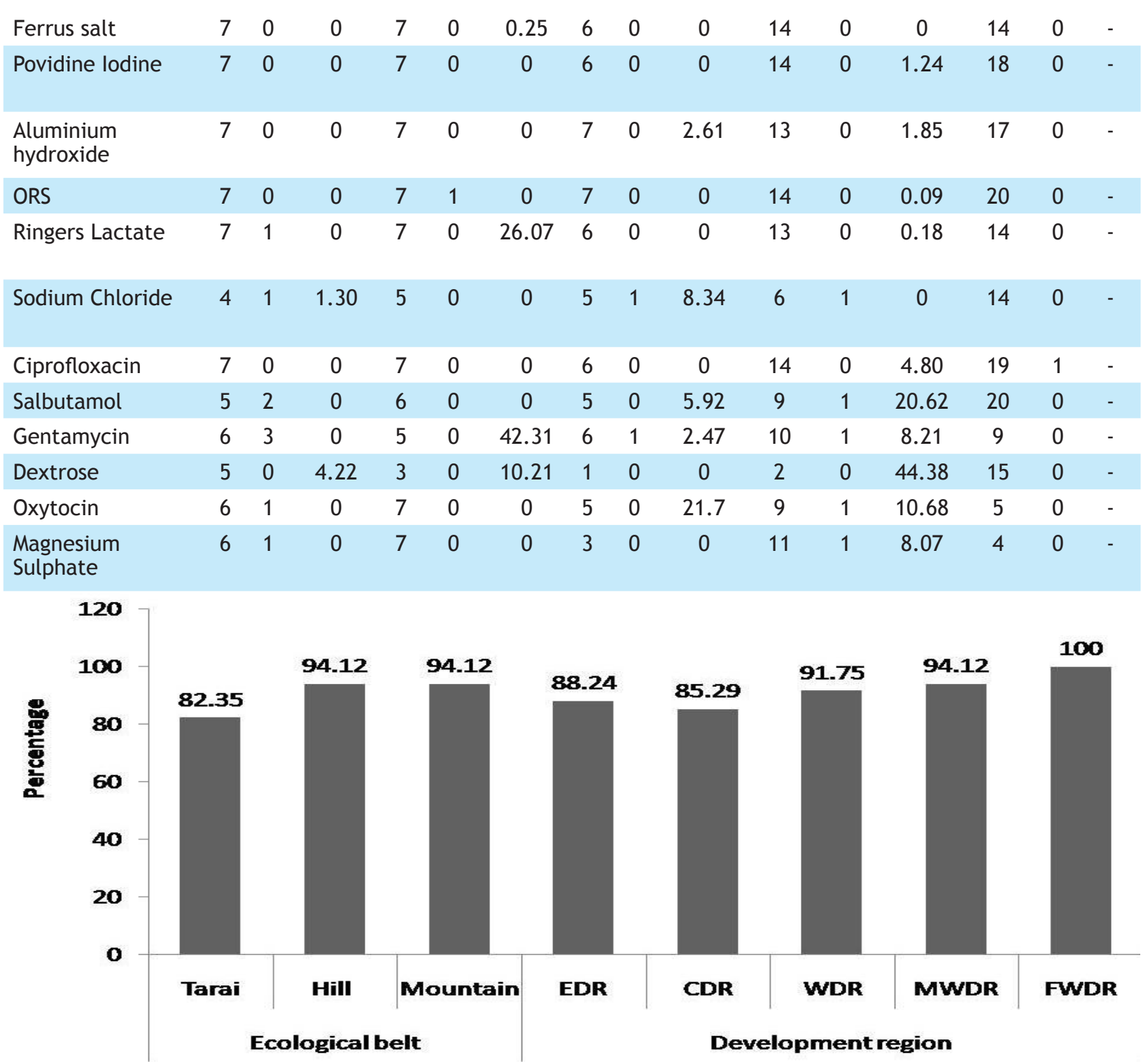

\section{Figure 1. Stock of medicine in district warehouse in Nepal.}

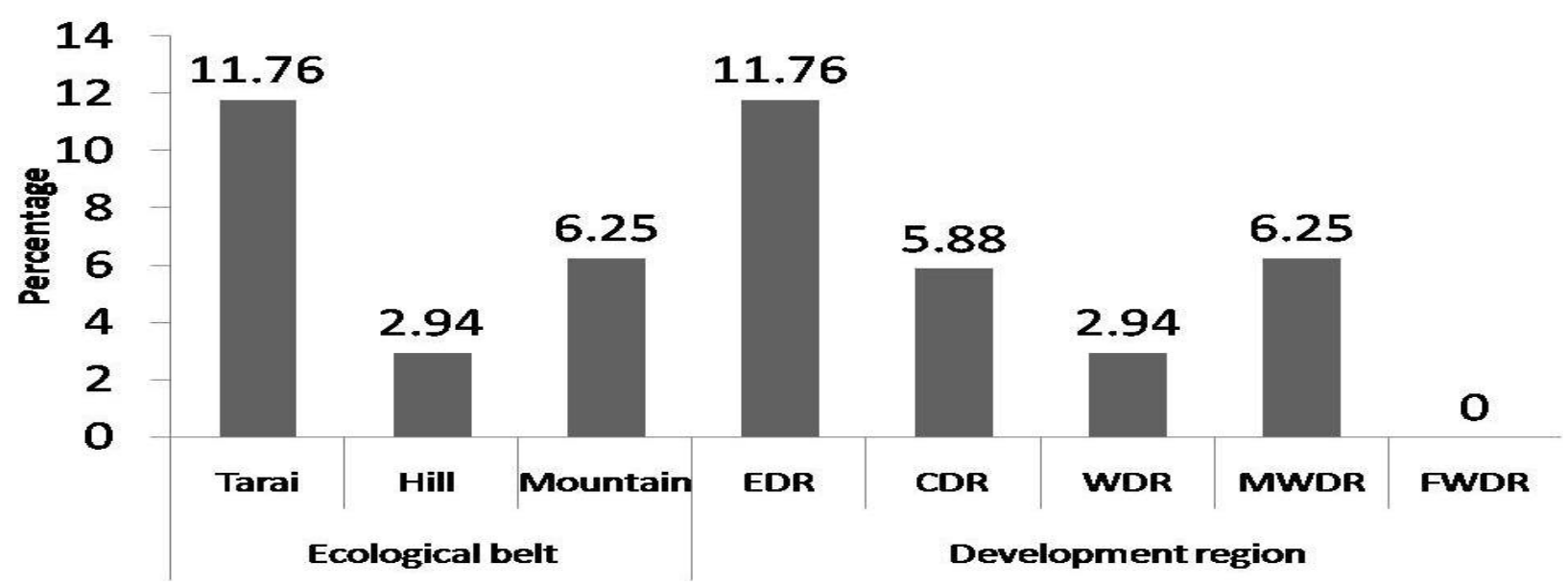

Figure 2. Expired medicines in district warehouse in Nepal. 


\section{DISCUSSION}

This study is one of the few studies exploring availability, expiry, and stock-out duration of 17 key essential medicines at both public and private health facilities in developing countries including Nepal. ${ }^{10-12}$ The study found that the average availability of medicines is well over $90 \%$ however the high number of expired medicines are present and even the stock out duration of medicines at some of the public health facilities are worrisome.

One of the national targets of the second-long term health plan is to achieve $100 \%$ availability of essential medicines at peripheral health facilities by $2017 .{ }^{13}$ So far, findings on availability of essential medicines reveal that Nepal close to achieving the target. Availability of medicines in district warehouse was found to be more than $90 \%$ in three of five development regions and two of three ecological belts. It was also found to be above $90 \%$ in all level of peripheral health facilities.

As baskets of medicines differ by country and thus results of research findings around the world are not strictly comparable. ${ }^{9}$ However, as this study follows the procedures recommended by the WHO, some studies can be referred. Nepal seem to have better availability of medicines compared to one study in India that had found that that the availability of essential medicines at primary health center ranged from $59 \%$ to $85 \%,{ }^{14}$ and even below $50 \%$ in other cases. ${ }^{15}$ Health service utilization can also be associated with the stock of medicine because health facilities with higher patient flow are more likely to run out of stock. This is further supported by another finding in our study that availability of medicines seems to increase as we move down the hierarchy of peripheral level health facilities with decreasing number of patient flow. In some cases, it reflects the trade-off with medicines pushed from district warehouse to peripheral health facilities. This is further supported by the reason that ecological belt and development region with lower stock in district warehouse seem to have comparatively better stock in peripheral health facilities. For example, CDR has the lowest stock of medicines in district warehouse while stock of medicines in peripheral health facilities is comparatively better.

Stock of medicines in private sector health facilities was lower than that in government health facilities in all three-ecological belt and all five development regions in this study. This hints towards the service utilization pattern of Nepalese population. This might have happened because people prefer to use essential medicines from public sector health facilities as they are provided free of cost and resulting low patient flow in private health facilities for essential medicines might have worked as disincentive to keep stock of essential medicines. However, it should be noted that private health facilities act as complementary to government health facilities and are option to people when essential medicines are not in stock in government health facilities. Absence of essential medicines in store of private health facilities may require people to travel longer distance to get medicines which may incur significant opportunity cost to patient.

Average stock-out duration of essential medicine in district warehouse was only 0.32 days. However, wide variations exist across development region and ecological belt. The average duration of stock out of medicine was 34 days in sub health post in mountain region and 20 days in MWDR. The longer duration of stock-out may be due to inability of district public health facility to deliver essential medicines to health facilities owing to difficult road conditions and lack of appropriate means of transportation. A study found that out of the total surveyed clients who used outpatient care and purchased drugs from a private pharmacy, nearly two-thirds (64\%) had done so because the drugs was not available at the public health facility. In the same study, 19\% took loans to cover costs. ${ }^{16}$ This shows that absence of essential medicines in public health facilities forces people, in some cases, to borrow money for accessing health services which may ultimately push them below poverty line. This can further increase inequity in health.

Some discrepancies also exist comparing stock of medicines and average stock-out duration although they can be expected to be inter related in most cases. Longer stock-out duration in general understanding translates to lower stock of medicines in health facilities. However, FWDR seem to have $100 \%$ of medicines in stock but the average stock-out duration was found to be around 10 days in SHP. This might because of seasonal variation is stock of medicines. Although medicines were available at the time of visit, they might have gone out of stock in some other point of time for example in rainy season when reaching many health facilities through road transportation becomes difficult in FWDR. Sometimes, the common practice is to take more medicines to dispensary showing absence of medicines in store register to order the medicines from district level before they reach normal medicine order point (even when the medicine in good amount in stock) specially when health facilities are geographically inaccessible and higher than normal time lag between demand and supply.

In contrast to our finding, a study had found high levels of expired drugs in health facilities and $60 \%$ of all expired drugs had been purchased locally and $30.6 \%$ from central procurement hinting that district (public) health offices had been purchasing drugs having short expiry dates. ${ }^{17}$ This might be the reason for presence 
of expired medicines in public health facilities in our study, too. The longer time duration from procurement of medicine to transporting to peripheral health facilities could be other potential reason for presence of expired medicines. The high volume of expired drugs can potentially diminish the efficiency of the free health care program. ${ }^{17}$ It is especially important to consider the issue expiry medicines in countries like Nepal with low literacy rate where people may not be able to read the expiry date of medicines and consume the medicines.

The findings are largely comparable to another study where 24 out of 40 essential medicines were found expired in at least one of total 52 health facilities. ${ }^{18} \mathrm{At}$ least nine drugs out of 17 drugs (52.9\% of total medicines) considered in this study were found expired in at least one health facilities at the time of visit. Although no differentiation was made in this study on whether the drugs expired in health facilities were procured at district level or central level, the proportion of health facilities with expired medicines seem to be lower in our study. Although the presence of expired medicines was relatively low in this study, regular monitoring of the peripheral health facility and improvement in drug supply system could further improve the scenario.

\section{CONCLUSIONS}

The availability of essential medicine was good with lesser proportion of expired medicine in public and private health facilities in Nepal. It is necessary to maintain the present status and take initiatives for further improvement of availability of essential medicines and reduce the presence of expired medicines.

\section{ACKNOWLEDGEMENTS}

WHO alliance/HQ, Geneva has provided financial support for this study.

\section{REFERENCES}

1. World Health Organization. The use of essential medicines (Including the Revised Model List of Essential Medicines) Ninth Report of the WHO Expert Committee. Geneva: World Health Organization Technical Report Series, No. 895.2000 .

2. Essential medicines [database on the Internet]. World Health Organization. 2015.[Full Text]

3. Bansal D, Purohit VK. Accessibility and use of essential medicines in health care: Current progress and challenges in India. J Pharmacol Pharmacother. 2013;4(1):13-8.[Full Text]

4. United Nations. Sustainable Development Goal 3 :Ensure healthy lives and promote well-being for all at all ages:
Division for Sustainable Development, UN-DESA. United Nations; 2016 [cited 2016]; [Full Text]

5. United Nations. Delivering on the Global partnership for achieving the Millennium Development Goals: MDG gap task force report. New York: United Nations2008.

6. Watal J. Access to Essential Medicines in Developing Countries: Does the WTO TRIPS Agreement Hinder It? Center for International Development,: Harvard University, Cambridge, MA, USA2000.[Full Text]

7. Zaidi S, Bigdeli M, Aleem N, Rashidian A. Access to essential medicines in Pakistan: policy and health systems research concerns. PloS ONE. 2013;8(5):e63515.[Full Text]

8. Harper I, Brhlikova P, Subedi MS, Bhattrai S. Drug procurement in Nepal working paper 1b,prepared for workshop on tracing pharmaceuticals in South East Asia: The Centre for International Public Health Policy: University of Edinburgh 2007.

9. World Health Organization. Operational package for assessing, monitoring and evaluating country pharmaceutical situations: Guide for coordinators and data collectors. Geneva: World Health Organization2007.[Full Text]

10. Mendis S, Fukino K, Cameron A, Laing R, Filipe Jr A, Khatib $\mathrm{O}$, et al. The availability and affordability of selected essential medicines for chronic diseases in six low-and middle-income countries. Bull World Health Organ. 2007;85(4):279-88.[Full Text]

11. Nunan M, Duke T. Effectiveness of pharmacy interventions in improving availability of essential medicines at the primary healthcare level. Trop Med Int Health. 2011;16(5):647-58.[Full Text]

12. Fentie M, Addisie Fenta FM, Oumer H, Belay S, Sebhat Y, Atinafu T, et al. Availability of Essential Medicines and Inventory Management Practice in Primary Public Health Facilities of Gondar Town, North West Ethiopia. Journal of Pharma Sci Tech. 2015;4:54-6. [Full Text]

13. Second long term health plan 1997-2017 :Perspective Plan for Health Sector Development. Kathmandu: Health Sector Reform Unit2007.

14. Maiti R, Bhatia V, Padhy BM, Hota D. Essential Medicines: An Indian Perspective. Indian J Community Med. 2015;40(4):223-32.[Full Text]

15. Kotwani A. Where are we now: assessing the price, availability and affordability of essential medicines in Delhi as India plans free medicine for all. BMC Health Serv Res. 2013;13(1):285. [Full Text] 
16. Mehata S, Baral SC, Chand PB, Singh DR, Poudel P, Barnett S. Nepal Household Survey 2012. Kathmandu: Ministry of Health and Population, Government of Nepal 2012.

17. Prasai DP. Review of Studies on Nepal's National Free Health Care Programme. Kathmandu, Nepal2013.

18. World Health Organization. Everybody business: strengthening health systems to improve health outcomes: WHO's framework for action. Geneva: World Health Organization2007.[Full Text] 